Table 2 Baseline plasma values and responses to luteinising hormone releasing hormone ( $L H R H)$ stimulation of follicle stimulating hormone (FSH) and LH (means (SD)) in 25 girls with premature thelarche, tested at age above 2 years, matched with controls and girls with true precocious puberty

\begin{tabular}{|c|c|c|c|c|}
\hline Group & Basal FSH $(\mathrm{mU} / \mathrm{ml})$ & Peak FSH $(m U / m l)$ & Basal LH $(\mathrm{mU} / \mathrm{ml})$ & Peak LH $(\mathrm{mU} / \mathrm{ml})$ \\
\hline Premature thelarche $(n=25)$ & $5 \cdot 6(1.9)$ & $31.7(15 \cdot 9)$ & $2(0 \cdot 7)$ & $10 \cdot 5(4 \cdot 2)$ \\
\hline Control subjects $(n=25)$ & $3.7(1.6)$ & $17.6(6.9)$ & $1.4(0 \cdot 8)$ & $5 \cdot 7(2)$ \\
\hline Precocious puberty $(n=25)$ & - & $23.6(9)$ & - & $30 \cdot 8(12.9)$ \\
\hline \multicolumn{5}{|l|}{ Significance of differences, $P$ : } \\
\hline Premature thelarche $v$ controls & $<0 \cdot(001$ & $<0 \cdot 001$ & $<0.001$ & $<0.001$ \\
\hline Premature thelarche $v$ precocious puberty & - & NS & - & $<0.001$ \\
\hline
\end{tabular}

NS $=$ not significant $(>0 \cdot 01)$.

reasonable to assume that both findings are related to ovarian secretion. This, in turn, would be dependent on hypothalamo-pituitary overactivation and directed to end organs, such as the mammary glands and the vaginal epithelium, with variable sensitivity to oestrogens. ${ }^{2-3}$ This hormonal hyperactivity may explain the increased height velocity in our girls with longer lasting breast development, regardless of the age at onset and the outcome of premature thelarche, and the fact that most patients were taller than their parents.

In our patients, premature thelarche had more often occurred during the first 2 years of life, as has also been reported by others. ${ }^{3}$ Furthermore, as observed by Ilicki et al, ${ }^{3}$ almost all the girls ( 21 out of 23) who later showed complete regression of breast enlargement, were those in whom breast enlargement had occurred before 2 years of age. The results of our study indicate that although signs of hormonal hyperactivity do exist in both groups of patients, premature thelarche with onset before age 2 years generally represents a transient and isolated phenomenon, while onset after this age represents the first sign of sexual development, leading more often to simple early puberty, but occasionally, as in three girls later excluded from the follow up group, $\stackrel{\circ}{ก}$ to precocious puberty.

We are grateful to Mr G Davi for laboratory investigations.

\section{References}

${ }^{1}$ Mills JL, Stolley PD, Davies J, Moshang T. Premature $ᄋ$ thelarche. Natural history and etiologic investigation. Am J Dis Child 1981;135:743-5.

${ }^{2}$ Landier F, Chaussain JL, Job JC. La prématurité mammaire isolée des filletes. Arch Fr Pédiatr 1983;40:549-52.

3 Ilicki A, Prager Lewin R, Kauli R, Kaufman H, Schachter A, Laron Z. Premature thelarche. Natural history and sex hormone secretion in 68 girls. Acta Paediatr Scand 1984;73:756-62.

${ }^{4}$ Kaufman RH, Leeds LJ. Cervical and vaginal cytology in the $\overrightarrow{.0}$ child and adolescent. Pediatr Clin North Am 1972;19:547- 80

Pasquino AM, Piccolo F, Scalamandrè A, Malvaso M, Or lani $R$, Boscherini B. Hypothalamic-pituitary gonadotros function in girls with premature thelarche. Arch Dis Chit 1980;55:941-4.

6 Reiter EO, Kaplan SL, Conte FA, Grumbach MM. Responsivity of pituitary gonadotropes to luteinizing hormone-releasing factor in idiopathic precocious puberty, precocious thelarche, $\frac{O}{\mathbb{D}}$ precocious adrenarche, and in patients treated with medroxy- $\varrho$ progesterone acetate. Pediatr Res 1975;9:111-6.

Correspondence to Dr A M Pasquino, Via Deruta 19, 00181 Rome, Italy.

Received 15 July 1985

\title{
Duration of admission for febrile convulsions?
}

\section{A L GREEN AND R MACFAUL}

\author{
Department of Paediatrics, Pinderfields General Hospital, Wakefield
}

SUMMARY Records of 199 children aged 5 to 71 months (mean 22.8) admitted after febrile convulsion were examined. Although 32 had recurrent convulsions (some before admission) none suffered a convulsion more than 24 hours after hospital admission.

Febrile convulsions are a frequent cause of hospital admission in childhood. Duration of admission will ${ }^{\circ}$ reflect the concern about the risk of a further convulsion and diagnosis and treatment of the cause $\underset{\omega}{N}$ of the fever that precipitated the fit. This study was undertaken to assess the proportion of children whoce suffered a repeated fit during the same febrile $\bar{\Phi}$ episode and to determine when, after hospital $\stackrel{?}{+}$ admission, the risk of recurrence was sufficiently 0 low to permit discharge from hospital. 


\section{Method}

The case notes of all children admitted with a simple febrile convulsion to this hospital between 1980 and 1983 were examined. Simple febrile convulsions were identified in 199 children aged 5 months to 6 years who had no persistent underlying neurological abnormality, no history of afebrile seizures, and no evidence of meningitis or encephalitis.

In all children admitted to this department with febrile convulsions full blood counts, throat swabs, urine cultures, and estimations of blood glucose and calcium are undertaken. Lumbar punctures are carried out according to the following criteria:

Table Repeated fits occurring after hospital admission $(n=19)$

\begin{tabular}{rlll}
\hline $\begin{array}{l}\text { Age } \\
\text { (months) }\end{array}$ & $\begin{array}{l}\text { Fit } \\
\text { duration } \\
\text { (mins) }\end{array}$ & $\begin{array}{l}\text { Time } \\
\text { after admission } \\
\text { of repeat fit } \\
\text { (hours) }\end{array}$ & $\begin{array}{l}\text { Duration of fever } \\
\text { after admission } \\
\text { (hours) }\end{array}$ \\
\hline 16 & 20 & $0 \cdot 1$ & 12 \\
15 & 10 & $0 \cdot 1$ & 2 \\
34 & 15 & $3 \cdot 5$ & 28 \\
17 & 15 & $4 \cdot 5$ & 30 \\
17 & 20 & $1 \cdot 5$ & 7 \\
18 & $0 \cdot 75$ & $19 \cdot 75$ & 22 \\
22 & $4 \cdot 5$ & $3 \cdot 5$ & 14 \\
10 & $2 \cdot 5$ & $1 \cdot 75$ & 40 \\
20 & 5 & $5 \cdot 25$ & 24 \\
20 & 5 & 22 & 33 \\
19 & 5 & 11 & 37 \\
37 & 5 & 1 & 48 \\
14 & $5 \cdot 5$ & $0 \cdot 1$ & 6 \\
6 & 15 & $4 \cdot 25$ & 20 \\
26 & 3 & 11 & 36 \\
19 & 2 & $15 \cdot 75$ & 80 \\
16 & 5 & $7 \cdot 5$ & 36 \\
47 & 4 & 6 & 8 \\
29 & 5 & $0 \cdot 01$ & 12 \\
\hline & & & \\
\hline & & & \\
\hline
\end{tabular}

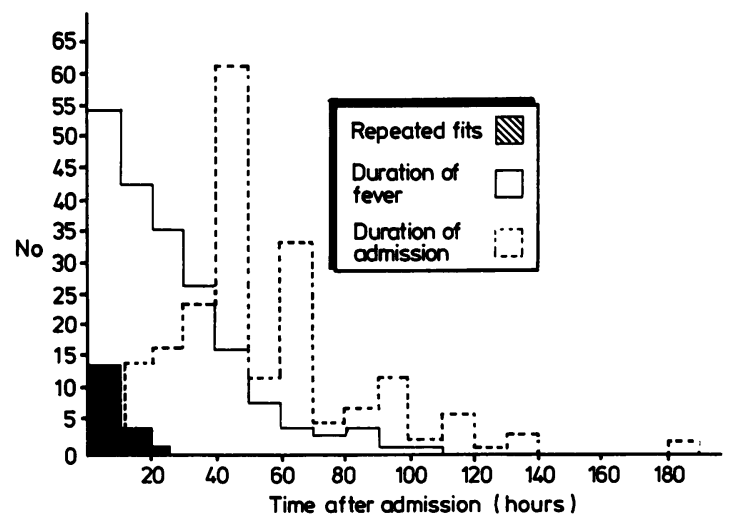

Figure Recurrence of fits, duration of fever, and length of hospital admission in 199 children admitted to hospital for febrile convulsions.
(1) In all children under 12 months of age;

(2) In all children under 18 months of age if there is no apparent cause for fever;

(3) In the presence of neck stiffness;

(4) If the fit lasted for 20 minutes or more or, if focal, for 10 minutes or more.

Lumbar punctures are repeated if the child seems disproportionately unwell during admission.

During the study it was usual to retain children in hospital for a 24 hour period after the last recorded fever.

\section{Results}

Repeated convulsions. Repeated convulsions in the febrile illness occurred in 32 children. In 13 of the 32 , the convulsion occurred before and in 19 after admission to hospital. Details of those 19 children in whom fits occurred after admission to hospital are given in the Table.

In the 199 children admitted with a febrile convulsion the mean duration of fever was 24.8 hours (range 0 to 106) and the mean duration of hospital admission was $55 \cdot 8$ hours (range 12 to 188 ) (see Figure).

Cause of fever. The causes of fever in the children were:

$\begin{array}{lr}\text { (a) Upper respiratory tract infection } & 81 \\ \text { (b) Viral infection } & 47 \\ \text { (c) 'Chest infection' } & 10 \\ \text { (d) Urinary tract infection } & 8 \\ \text { (e) Otitis media } & 37 \\ \text { (f) Septicaemia } & 2 \\ \text { (g) Exanthema } & 5 \\ \text { (h) Gastroenteritis } & 8 \\ \text { (i) Mumps } & 1\end{array}$

Associated features. Associated features in those children who had repeated fits were examined to determine whether it was possible to predict a higher risk of recurrent febrile convulsion. There was no significant relation between recurrent fits and height of fever on admission, duration of initial fit, cause of fever, past history of febrile fits, or age of the child.

\section{Discussion}

The Table shows that no child suffered a repeat febrile convulsion more than 24 hours after admission to hospital, despite the persistence of fever in 78 children (nine of whom had experienced a repeat convulsion within 24 hours of admission) (see Figure). 
Repeated fits occurred in 32 children in this study; in 13 before hospital admission. The repeated fits were of short duration (mean 7.75 minutes, range 0.75 to 20$)$. The incidence of repeated fits $(16 \cdot 1 \%)$ compares with $16 \cdot 2 \%$ in the study by Nelson and Ellenberg. ${ }^{1}$

Diagnosis of the cause of fever was helped by our active investigative policy of excluding meningitis. Although we are aware of the differing views on the value of routine lumbar punctures in studies reviewed by Kudrjavcev, ${ }^{2}$ our policy has been adopted as a safety measure in a hospital with relatively inexperienced resident staff. The results of this study suggest that it is safe to discharge children (even if still febrile) when they have been observed for 24 hours after a febrile convulsion-provided, of course, they are reasonably well in themselves and a diagnosis of cause of the fever established. The risk of recurrent febrile convulsions 24 hours after admission seems to be very low (0/199).

We thank Dr C S Livingstone for his permission to report details of some of his patients in this study.

References
1 Nelson KB, Ellenberg JH. Predictors of epilepsy in children who
have experienced febrile seizures. N Engl J Med
1976;295:1029-33.
2 Kudrjavcev T. Skull x rays and lumbar puncture in a young child
presenting with a seizure and fever. In: Nelson KB, Ellen-
berg JH, eds. Febrile seizures. New York: Raven Press,
1981:221-9.

Correspondence to Dr R MacFaul, Pinderfields General Hospital, Wakefield, West Yorkshire WF1 4DG.

Received 22 July 1985

\title{
Type V glycogen storage disease
}

\author{
J WILLIAMS AND G HOSKING
}

Glan Clwyd District General Hospital, and The Ryegate Centre and Children's Hospital, Sheffield

\begin{abstract}
SUMmaRY We describe three children with type $\mathrm{V}$ glycogen storage disease, who were reluctant to climb hills. We suggest that this condition, usually described as being of adult onset, can often be diagnosed in childhood.
\end{abstract}

Myopathy associated with defective glycogen breakdown was first described by McArdle in 1951. ${ }^{1}$ Absent muscle phosphorylase activity was subsequently shown. ${ }^{2}$ Standard texts suggest that the condition rarely presents in childhood and diagnosis is usually established in adolescence or later. We describe three children with type $\mathrm{V}$ glycogen storage disease, one diagnosed at the age of 8 years and two at the age of 10 .

\section{Case histories}

Case 1. An 8 year old girl was referred with a four year history of disinclination to walk more than a short distance, particularly uphill. Short rests seemed helpful in allowing her to continue. She had always been considered clumsy as a small child and fell often.

Examination showed a mild tremor of both hands and pain with contraction of finger flexors within 20 seconds of beginning exercise. Creatine kinase activity was raised at $1500 \mathrm{IU} / \mathrm{l}$ and $3234 \mathrm{IU} / \mathrm{l}$ on consecutive measurements. Standard test for ischaemic lactate concentrations showed an in- $\frac{\circ}{D}$ appropriately low rise in blood lactate concentration. No muscle phosphorylase activity was detected by muscle biopsy.

Case 2. This 10 year old girl had a long history of slow walking (particularly uphill) and associated leg cramps. Physical examination was unremarkable. Creatine kinase activity was raised initially at 7548 IU/l, though it was subsequently measured at 374 IU/l. Test for ischaemic lactate concentration showed no appreciable rise in blood lactate values, and no muscle phosphorylase activity was detected by muscle biopsy.

Case 3. A 10 year old girl was referred with a long $N$ history of pain and weakness below the knee. This had become more pronounced in the preceding 18 응 months, and she needed rests on walking any great $\mathrm{\omega}$ distance. No abnormalities were noted on examination. Creatine kinase activity was raised at $650 \mathrm{IU} / 1$, and tests for ischaemic lactate concentration showed no appreciable rise in blood lactate values. Muscle $\stackrel{\mathcal{P}}{?}$ phosphorylase activity was absent in the muscle 0 biopsy. 